\title{
Addendum: da Silva, J.L.F.; et al. The Lisbon Supramolecular Green Story: Mechanochemistry towards New Forms of Pharmaceuticals. Molecules 2020, 25, 2705
}

\author{
João Luís Ferreira da Silva ${ }^{1,2} \mathbb{D}$, M. Fátima Minas da Piedade ${ }^{1,3}$, Vânia André ${ }^{1,4} \mathbb{D}^{\mathbb{2}}$, Sofia Domingos ${ }^{1}$, \\ Inês C. B. Martins ${ }^{1}$ and M. Teresa Duarte ${ }^{1,2, *(D)}$
}

check for

updates

Citation: da Silva, J.L.F.; da Piedade, M.F.M.; André, V.; Domingos, S.; Martins, I.C.B.; Duarte, M.T. Addendum: da Silva, J.L.F.; et al. The Lisbon Supramolecular Green Story: Mechanochemistry towards New Forms of Pharmaceuticals. Molecules 2020, 25, 2705. Molecules 2021, 26, 419. https://doi.org/10.3390/molecules 26020419

Received: 30 July 2020

Accepted: 14 August 2020

Published: 14 January 2021

Publisher's Note: MDPI stays neutral with regard to jurisdictional clai$\mathrm{ms}$ in published maps and institutional affiliations.

Copyright: $@ 2021$ by the authors. Licensee MDPI, Basel, Switzerland. This article is an open access article distributed under the terms and conditions of the Creative Commons Attribution (CC BY) license (https:// creativecommons.org/licenses/by/ $4.0 /)$.
1 Centro de Química Estrutural, Instituto Superior Técnico, Universidade de Lisboa, Avenida Rovisco Pais, 1049-001 Lisboa, Portugal; joao.luis@ist.utl.pt (J.L.F.d.S.); mdpiedade@fc.ul.pt (M.F.M.d.P.); vaniandre@tecnico.ulisboa.pt (V.A.); sofiadomingos@ff.ulisboa.pt (S.D.); ines.martins@tecnico.ulisboa.pt (I.C.B.M.)

2 Departamento de Engenharia Química, Instituto Superior Técnico, Universidade de Lisboa, Avenida Rovisco Pais, 1049-001 Lisboa, Portugal

3 Departamento de Química e Bioquímica, Faculdade de Ciencias, Universidade de Lisboa, 1649-016 Lisboa, Portugal

4 Associação do Instituto Superior Técnico para a Investigação e Desenvolvimento (IST-ID), Av. Rovisco Pais, 1049-003 Lisboa, Portugal

* Correspondence: teresa.duarte@tecnico.ulisboa.pt

The authors wish to add funding project UIDB/00100/2020 into the Funding section of this paper [1]. The corrected funding is provided below:

Funding: This research was funded by Fundação para a Ciência e a Tecnologia, grant numbers UIDB/00100/2020, PEST-OE/QUI/UI0100/2013 (CQE) and RECI/QEQ-QIN70189/2012 (M.T.D. as PI), V.A. was funded by SFRH/BPD/78854/2011 and CEECIN/02001/2017 post-doctoral grants; S.D. was funded by Research Grant PTDC/CTM-BPC/122447/2010; I.C.B.M. was funded by PhD grant SFRH/BD/93140/2013 and S.Q. by PhD grant SFRH/BD/100024/2014.

We apologize to the Molecules readership for this error, which in no way affects the scientific content of the paper.

\section{Reference}

1. Da Silva, J.L.F.; da Piedade, M.F.M.; André, V.; Domingos, S.; Martins, I.C.B.; Duarte, M.T. The Lisbon Supramolecular Green Story: Mechanochemistry towards New Forms of Pharmaceuticals. Molecules 2020, 25, 2705. [CrossRef] 